\title{
Pergerakan Kadmium (Cd) melalui Tanah Baki Granit Terpadat Menggunakan Kaedah Kolum Turasan Mini
}

(The Movement of Cadmium (Cd) through Compacted Granitic Residual Soil using Mini Column Infiltration Technique)

\author{
NUR ‘AISHAH ZARIME* \& WAN ZUHAIRI WAN YAACOB
}

\begin{abstract}
ABSTRAK
Penyelidikan ini mengkaji tingkah laku cadmium (Cd) melalui tanah baki granit yang dipadatkan. Sampel tanah baki granit telah diambil di kawasan Broga, Selangor dan dikaji menggunakan tiga kaedah ujian utama iaitu; ujian fizikal (taburan saiz, butiran, had-had Atterberg, graviti tentu, pemadatan dan kebolehtelapan), ujian kimia (pH, bahan organik, luas permukaan spesifik (SSA) dan kadar pertukaran kation (CEC) serta ujian mini kolum turasan. Melalui ujian kolum turasan, konsep kebolehtelapan turus menurun digunakan yang melibatkan tiga faktor iaitu halaju/daya-G, ketebalan sampel dan jenis larutan yang digunakan. Graf lengkung bulus menunjukkan kepekatan Cd dalam tanah baki granit semakin meningkat dengan peningkatan halaju. Urutan kapasiti penjerapan semakin meningkat terhadap kadar putaran alat emparan/daya tarikan graviti (G); 230G>520G>920G>1440G. Pergerakan logam berat melalui tanah baki juga meningkat dengan peningkatan halaju/daya-G. Lengkung bulus juga menunjukkan pergerakan Cd secara songsang dengan ketebalan lapisan tanah di dalam kolum. Masa penembusan bagi ketebalan $20 \mathrm{~mm}$ juga lebih lama berbanding ketebalan 15 dan $10 \mathrm{~mm}$. Manakala jumlah Cd yang terjerap oleh tanah baki granit dalam larutan campuran adalah rendah berbanding larutan tunggal (masa yang singkat untuk menembusi lengkung bulus). Tanah baki granit juga mempunyai kapasiti penampanan yang rendah $\left(\mathrm{pH}_{\text {final }}=4\right.$ - 7). Kajian ini menunjukkan bahawa pencirian fiziko-kimia dan sifat penjerapan tanah dengan menggunakan ujian mini kolum turasan mempunyai kaitan yang kuat untuk mencirikan tanah baki granit untuk dijadikan pelapik lempung tereka bentuk.
\end{abstract}

Kata kunci: Kadmium; lengkung bulus; mini kolum turasan; tanah baki granit

ABSTRACT

This research investigates the behaviour of cadmium $(C d)$ through compacted granite residual soils. Granite residual soil (BGR) was collected in Broga, Selangor and was subjected to three main test; physical test (particle size distribution, Atterberg Limit, specific gravity, compaction and permeability), chemical tests ( $\mathrm{pH}$, organic matter, specific surface area (SSA) and cation exchange capacity (CEC)) and mini column infiltration test. Column test followed the falling head permeability concepts where different g-force, samples thickness and different types of solutions were used in this study. Breakthrough curves show the concentration of Cd in granite residual soil becomes higher with the increasing of $g$-force. The adsorption capacity is increasing to the rotation rate of the centrifugal/gravity ranked as; $230 G>520 G>920 G>1440 G$. Mobility of Cd through granite residual soil also become higher with increasing g-force. The breakthrough curves also showed that mobility of Cd inversely correlated with the thickness of the soil layer in the column. Penetration time through soil thickness $20 \mathrm{~mm}$ was longer than the 15 and $10 \mathrm{~mm}$ thickness. The amount of Cd adsorbed by granite residual soil in mixture solutions was lower than in single solution (less time to penetrate the breakthrough curve). Granite residual soil also has low buffering capacity $\left(\mathrm{pH}_{\text {final }}=4\right.$ - 7). The study concluded that physical-chemical characterization and sorption properties of soil using mini column infiltration test have very good linked to characterize granite residual soils material to functions as engineered clay liner.

Keywords: Breakthrough curve; cadmium; granite residual soil; mini column infiltration test

\section{PENDAHULUAN}

Penyelidikan berkaitan pelapik lempung telah dikaji oleh ramai penyelidik, antaranya ialah Chalermyanont et al. (2009); Devulapalli \& Reddy (1996) dan Xie et al. (2009. Pelapik lempung bertindak melemahkan pengangkutan bahan pencemar dan menyelesaikan masalah penyusupan cecair sisa di tapak pelupusan (Yong et al. 2001). Bahan geologi iaitu tanah baki telah dipilih sebagai pelapik lempung disebabkan kuantitinya yang banyak, mudah diperoleh dan harga yang murah (Rosli et al. 2008). Selain itu, tanah baki mempunyai ciri fiziko-kimia yang membolehkan tanah baki ini berpotensi untuk merencatkan pengaliran bahan pencemar daripada menyusup masuk ke bawah tanah. Tanah baki juga boleh dipadatkan kepada ketertelapan yang sangat rendah iaitu kurang daripada $1 \times 10^{-9} \mathrm{~m} / \mathrm{s}$ dan bertindak sebagai perlindungan terakhir 
untuk air bawah tanah terhadap bahan pencemar (Zuhairi et al. 2008a). Menurut Yong et al. (2001), tanah yang mempunyai ketertelapan yang rendah dan penjerapan logam yang tinggi berpotensi untuk menjadi pelapik lempung yang efektif. Kini, penyelidikan tentang pergerakan logam berat dengan menggunakan alat emparan geoteknik semakin berkembang dan telah digunakan oleh ramai penyelidik seperti Alshaebi et al. (2010), Antoniadis dan Mckinley (2000) dan Kumar (2006). Penyelidik terdahulu juga telah membuktikan alat emparan geoteknik memberikan keputusan eksperimen yang sangat baik dalam mengkaji pengangkutan bahan pencemar melalui tanah berbutiran halus (Antoniadis \& Mckinley 2000). Melalui kajian ini, dapat diketahui pergerakan logam berat $(\mathrm{Cd})$ melalui tanah baki granit dengan menggunakan kaedah mini kolum turasan. Selain itu, melalui penentuan nilai pemalar penjerapan, $\mathrm{K}_{\mathrm{d}}$, potensi tanah baki granit untuk dijadikan bahan penjerap dapat ditentukan. Kajian ini memilih logam berat $\mathrm{Cd}$ disebabkan ia mempunyai kepelbagaian tingkah laku dalam tanah. Pengumpulan Cd di dalam tubuh manusia juga akan menyebabkan ciritbirit dan kekejangan otot, kemerosotan buah pinggang, masalah paru-paru kronik dan kecacatan rangka (Mohan \& Singh 2002).

\section{BAHAN DAN KAEDAH}

\section{BAHAN}

Bahan yang digunakan dalam kajian ini adalah bahan geologi iaitu tanah baki granit (BGR). Persampelan tanah baki granit dilakukan di kawasan Broga, Selangor. Tanah baki granit ini akan dikeringkan dahulu dan kemudian diayak kepada saiz $0.125 \mathrm{~mm}$ sebelum digunakan untuk analisis makmal. Analisis fiziko-kimia dijalankan mengikut Kaedah British Standard, BS1377 (1990) dan analisis penjerapan kolum turasan dijalankan mengikut kaedah oleh Antoniadis et al. (2007).

\section{KAEDAH MINI KOLUM TURASAN}

Kaedah ini dijalankan berpandukan Antoniadis dan Tsadilas (2007) dengan menggunakan alat pengempar Sigma 416S, rotor hayun-keluar dan alat kolum turasan yang tahan karat.
Kolum turasan ini terbahagi kepada dua iaitu bahagian atas dan bawah seperti yang ditunjukkan dalam Rajah 1. Bahagian atas adalah takungan larutan unsur pencemar (influen) manakala bahagian bawah adalah larutan hasil daripada proses penyusupan melalui lapisan tanah yang juga dikenali sebagai larutan efluen. Larutan pencemar iaitu cadmium (II) nitrat disediakan dengan kepekatan $500 \pm 25 \mathrm{mg} / \mathrm{L}$. Sebanyak $10 \mathrm{~g}$ sampel tanah dicampurkan dengan air ternyahion sehingga campuran menjadi separuh cecair dan dibiarkan semalaman. Kemudian, sampel tanah dimasukkan ke dalam kolum larut dan diempar. Lapisan tanah akan terbentuk dan larutan efluen dibuang. Larutan influen (1 isi padu liang) dimasukkan ke dalam kolum dan diempar sekali lagi sehingga kesemua larutan pencemar menembusi lapisan tanah. Ujian ini dilakukan sehingga 60 isi padu liang (PV). Larutan efluen dianalisis menggunakan alatan spektrometer jisim induktif gandingan plasma (ICPMS) model Perkin-Elmer Sciex ELAN 9000.

\section{PEKALI TABURAN $\left(\mathrm{K}_{\mathrm{d}}\right)$}

Persamaan linear digunakan untuk menggambarkan bahan larut penjerapan;

$$
\mathrm{C}_{\mathrm{ads}}=\frac{\left(\mathrm{C}_{\mathrm{o}}-\mathrm{C}_{\mathrm{aq}}\right) \mathrm{V}}{\mathrm{M}},
$$

dengan $\mathrm{C}_{\text {ads }}$ adalah jumlah logam yang dijerap per unit jisim tanah $(\mathrm{mg} / \mathrm{kg}) ; \mathrm{C}_{\mathrm{o}}$ dan $\mathrm{C}_{\mathrm{aq}}$ adalah kepekatan dalam larutan awal dan akhir tindak balas $(\mathrm{mg} / \mathrm{L}) ; \mathrm{V}$ adalah isi padu larutan yang digunakan (mL); dan M adalah jisim tanah (g).

Pekali penjerapan, $K_{d}(\mathrm{~L} / \mathrm{kg})$ menerangkan pembahagian keseimbangan logam antara fasa pepejal dan cecair (Antoniadis et al. 2007). Pengiraan pekali penjerapan, $\mathrm{K}_{\mathrm{d}}$ ditentukan melalui persamaan $\mathrm{C}_{\mathrm{ads}}=\mathrm{K}_{\mathrm{d}} / \mathrm{C}_{\mathrm{aq}}$ (Alther 2002; Cheyns et al. 2010; Devulapalli \& Reddy 1996).

\section{HASIL DAN PERBINCANGAN}

\section{SIFAT FIZIK DAN KIMIA}

Hasil keputusan analisis ujian fizikal terhadap tanah baki granit ditunjukkan dalam Jadual 1. Tanah baki granit
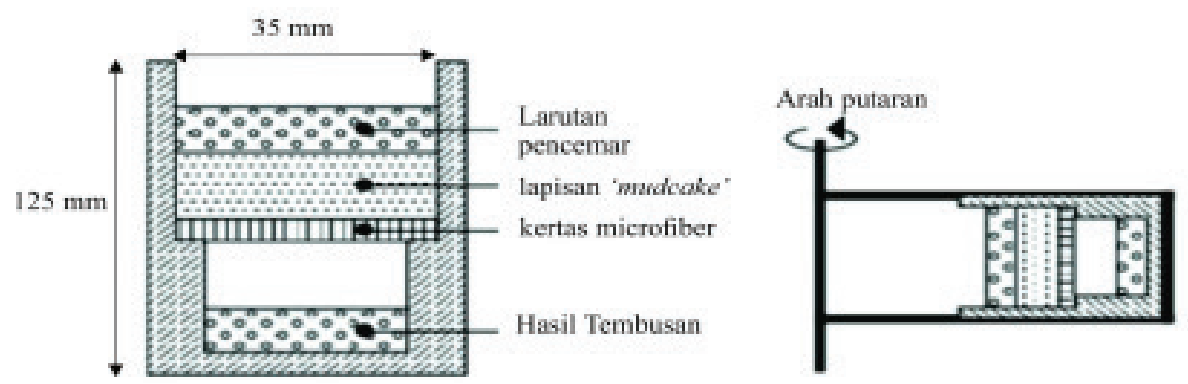
JADUAL 1. Sifat fizik tanah baki granit, (BGR)

\begin{tabular}{lc}
\hline Sifat fizik & BGR \\
\hline Taburan saiz butiran: & \\
Pasir (\%) & $54-63$ \\
Kelodak (\%) & $32-42$ \\
Lempung (\%) & $1-6$ \\
Had-had Atterberg: & \\
Had plastik (\%) & $38.01-38.69$ \\
Had cecair $(\%)$ & $48.50-50.00$ \\
Indeks keplastikan $(\%)$ & $9.90-11.99$ \\
Graviti tentu & $2.50-2.59$ \\
Ketumpatan kering optimum $\left(\mathrm{g} / \mathrm{cm}^{3}\right)$ & $1.64-1.71$ \\
Kebolehtelapan $(\mathrm{m} / \mathrm{s})$ & $2.08 \times 10^{-06}$ \\
\hline
\end{tabular}

menunjukkan peratusan pasir yang tinggi iaitu berjulat antara 54-63\% manakala peratusan lempung memberikan bacaan julat yang rendah iaitu antara 1-6\%. Atanassova (1999) menyatakan kadar penjerapan bagi tanah berbutiran kasar adalah lebih rendah berbanding dengan tanah berbutiran halus. Indeks keplastikan bagi tanah baki granit adalah antara 9.90-11.99\% dan tergolong dalam keplastikan sederhana. Tanah baki granit juga menunjukkan julat nilai graviti tentu dan ketumpatan kering optimum masing-masing berjulat dari 2.50-2.59 dan 1.64-1.71 g/ $\mathrm{cm}^{3}$. Menurut Chalermyanont et al. (2009), nilai graviti tentu bergantung kepada kandungan lempung dalam tanah. Peningkatan kandungan lempung dalam tanah menyebabkan ruang pori semakin sempit dan mengurangkan nilai graviti tentu. Nilai kebolehtelapan bagi tanah baki granit adalah $2.08 \times 10^{-06} \mathrm{~m} / \mathrm{s}$. Tanah baki granit bersifat lebih telap disebabkan ia didominasi oleh saiz butiran kasar. Keputusan ujian sifat kimia ditunjukkan dalam Jadual 2. Tanah baki granit mempunyai nilai $\mathrm{pH}$ tanah 5.32-5.54 iaitu sedikit berasid. Menurut Kouame et al. (2010), nilai pH menentukan tingkah laku sesuatu logam. Bagi nilai pH yang rendah, kebanyakan logam berat berada dalam keadaan bergerak dan menyebabkan penjerapan logam berat semakin berkurang. Tanah baki granit juga mempunyai nilai peratusan bahan organik tanah, nilai SSA dan CEC yang rendah, masing-masing berjulat antara $0.39-0.50 \%, 17.96-21.93 \mathrm{~m}^{2} / \mathrm{g}$ dan 0.79-1.35 meq/100g. Kim et al. (2007) melaporkan bahawa bahan organik lebih banyak terkumpul dalam saiz butiran halus. Peratusan lempung yang rendah menyebabkan kandungan bahan organik dalam tanah baki granit adalah rendah. Ia juga mengurangkan nilai luas permukaan tanah dengan semakin berkurang luas permukaan tanah, semakin berkurang luas permukaan sentuhan iaitu tapak aktif bagi aktiviti penjerapan ion positif. Ini menyebabkan kadar penjerapan bagi tanah baki granit berkurang. Pertukaran kation turut berlaku pada permukaan mineral lempung dan bahan organik tanah yang bercas negatif (Chalermyanont et al. 2009). Oleh itu semakin berkurang nilai CEC, semakin berkurang kadar penjerapan logam berat.
JADUAL 2. Sifat kimia tanah baki granit, (BGR)

\begin{tabular}{lc}
\hline Sifat kimia & BGR \\
\hline $\mathrm{pH}$ & $5.32-5.54$ \\
Bahan organik tanah $(\%)$ & $0.39-0.50$ \\
$\mathrm{SSA}\left(\mathrm{m}^{2} / \mathrm{g}\right)$ & $17.96-21.93$ \\
$\mathrm{CEC}(\mathrm{meq} / 100 \mathrm{~g})$ & $0.79-1.35$ \\
\hline
\end{tabular}

SSA: Luas permukaan spesifik; CEC: Kapasiti pertukaran kation

\section{UJIAN MINI KOLUM TURASAN}

Ujian mini kolum turasan dianalisis melalui graf lengkung bulus iaitu dengan memplot kepekatan relatif $(\mathrm{Ce} / \mathrm{Co})$ melawan isi padu liang (PV). Ce/Co adalah nisbah antara kepekatan efluen (Ce) dengan kepekatan awal larutan logam berat (Co). Jumlah penembusan $\mathrm{Cd}$ berlaku apabila nilai $\mathrm{Ce} / \mathrm{Co}$ adalah bersamaan dengan $1(\mathrm{Ce} / \mathrm{Co}=1)$. Bagi lengkung bulus kurang dari $1(\mathrm{Ce} / \mathrm{Co}<1)$, ia menunjukkan penjerapan logam berat yang lebih tinggi. Rajah 2(b) menunjukkan pada halaju $2500 \mathrm{rpm}$, masa penembusannya adalah pada $10 \mathrm{PV}$ dan penembusannya adalah $1(\mathrm{Ce} /$ $\mathrm{Co}=1$ ). Ini menunjukkan pada halaju/daya-G yang tinggi, pergerakan $\mathrm{Cd}$ melalui tanah adalah lebih cepat. Menurut Alemayehu dan Lennartz (2009), pergerakan logam berat (Cd) melalui tanah adalah cepat disebabkan oleh masa interaksi antara logam berat (Cd) dan partikel tanah berkurang dan menyebabkan penjerapan logam berat $(\mathrm{Cd})$ turut berkurang.

\section{FAKTOR HALAJU/ DAYA-G}

Rajah 2 menunjukkan kesan pengaruh halaju/daya-G terhadap terhadap tanah baki granit (BGR) apabila diempar. Kesemua graf mempunyai trend yang sama dengan lengkung penjerapan adalah linear pada isi padu liang yang rendah dan menjadi malar pada isi padu liang yang lebih tinggi, iaitu apabila penjerapan maksimum dicapai dan permukaan penjerapan sudah tepu dengan logam berat (Liew \& Zuhairi 2010). Rajah 2 juga menunjukkan bahawa halaju/daya-G mempengaruhi kepekatan relatif sampel tanah baki granit (BGR). Semakin bertambah halaju yang dikenakan pada sampel tanah baki granit dalam sel kolum semakin bertambah kepekatan relatif. Perbezaan antara setiap lengkung dengan halaju yang berbeza adalah kecil dan tidak terlalu ketara. Walau bagaimanapun, lengkung pada Rajah 2(c) iaitu pada halaju 2000 rpm menunjukkan kepekatan yang paling tinggi. Ini disebabkan berlakunya keretakan pada lapisan tanah semasa proses emparan dan membolehkan larutan pencemar menyusup masuk ke dalam retakan. Taburan saiz butiran tidak homogen dan pemadatan lapisan tanah secara tidak sekata boleh menyebabkan kekuatan lapisan tanah tidak sama dan menyebabkan keretakan pada lapisan tanah. Urutan kapasiti penjerapan yang semakin menaik adalah seperti berikut; $2500 \mathrm{rpm}(1440 \mathrm{~g})<2000 \mathrm{rpm}$ $(920 \mathrm{~g})<1500 \mathrm{rpm}(520 \mathrm{~g})<1000 \mathrm{rpm}(230 \mathrm{~g})$. Zuhairi et al. (2008a) juga menyatakan kepekatan Cd yang rendah 
(lengkung berhampiran dengan paksi-x) menunjukkan kapasiti penjerapan yang lebih tinggi. Cd dalam tanah baki granit juga bersifat aktif dan kurang terjerap dan ia turut dipengaruhi oleh sifat fiziko-kimia tanah baki granit.

\section{FAKTOR KETEBALAN SAMPEL}

Kesan ketebalan terhadap pergerakan Cd ditunjukkan dalam Rajah 3. Lengkung penembusan menunjukkan pergerakan $\mathrm{Cd}$ adalah secara songsang dengan ketebalan lapisan tanah di dalam kolum turasan. Rajah 3(b), pada halaju $1500 \mathrm{rpm}$ menunjukkan ketebalan $20 \mathrm{~mm}$ mempunyai pergerakan $\mathrm{Cd}$ yang paling tinggi diikuti oleh 15 dan $10 \mathrm{~mm}$. Masa penembusan untuk tanah berketebalan $20 \mathrm{~mm}$ juga adalah lama berbanding 15 dan $10 \mathrm{~mm}$. Rajah 3(b) menunjukkan masa penembusan bagi tanah $20 \mathrm{~g}$ (20 $\mathrm{mm})$ adalah pada $24 \mathrm{PV}(\mathrm{Ce} / \mathrm{Co}=1.23)$, diikuti oleh tanah $15 \mathrm{~g}(15 \mathrm{~mm})$ dan $10 \mathrm{~g}(10 \mathrm{~mm})$ masing-masing pada $16 \mathrm{PV}$ $(\mathrm{Ce} / \mathrm{Co}=0.89)$ dan $12 \mathrm{PV}(\mathrm{Ce} / \mathrm{Co}=0.57)$. Menurut Xie et al. (2009), penembusan adalah lebih lama sekiranya ketebalan tanah meningkat disebabkan oleh bahan pencemar memerlukan lebih masa untuk menyusup masuk dalam sistem tanah. Bagi Rajah 3(a) pada halaju 1000 rpm dan Rajah 3(d) pada halaju 2500 rpm, lengkung penembusan tidak mengikut teori iaitu masing-masing pada ketebalan 15 dan $10 \mathrm{~mm}$. Ini disebabkan berlakunya retakan pada lapisan dan menyebabkan bahan pencemar menyusup masuk ke dalam retakan.

\section{FAKTOR JENIS LARUTAN}

Rajah 4 menunjukkan graf lengkung penembusan bagi unsur Cd dalam larutan berbeza. Ketiga-tiga graf menunjukkan jumlah $\mathrm{Cd}$ yang dijerap oleh tanah baki granit dalam larutan campuran adalah rendah berbanding larutan tunggal. Menurut Markiewicz-Patkowska et al. (2005) dan Wan Zuhairi dan Abdul Rahim (2007), perbezaan dalam penjerapan logam oleh kedua-dua sistem ini adalah disebabkan oleh persaingan antara logam berat untuk mendapatkan tempat serapan yang terhad dalam tanah. Bagi unsur Cd dalam larutan campuran, ia perlu bersaing untuk mendapatkan tempat di dalam komponen-komponen aktif tanah (tapak penjerapan). Masa penembusan bagi larutan campuran juga lebih cepat berbanding larutan tunggal. Contohnya, jumlah penembusan (Rajah 4(a)) pada halaju $1000 \mathrm{rpm}$ iaitu bagi larutan campuran adalah $14 \mathrm{PV}(\mathrm{Ce} / \mathrm{Co}=0.90)$ manakala jumlah penembusan bagi larutan tunggal adalah $22 \mathrm{PV}(\mathrm{Ce} / \mathrm{Co}=0.61)$. Ini disebabkan oleh kebanyakan ion logam berat dalam larutan campuran bersedia untuk berinteraksi serta merta dan menyebabkan tapak kosong cepat dipenuhi oleh ion positif.

\section{$\mathrm{K}_{\mathrm{d}}$ DALAM JENIS LARUTAN TUNGGAL ATAU LARUTAN CAMPURAN}

Merujuk kepada Jadual 3, bagi ketebalan $10 \mathrm{~mm}$ dan halaju $2000 \mathrm{rpm}$, nilai $\mathrm{K}_{\mathrm{d}}$ dalam larutan tunggal (500 ppm) adalah lebih tinggi iaitu $0.793 \mathrm{~L} / \mathrm{kg}$ berbanding dengan nilai $\mathrm{K}_{\mathrm{d}}$ bagi larutan campuran $(500 \mathrm{ppm})$ iaitu $0.420 \mathrm{~L} / \mathrm{kg}$. Ini

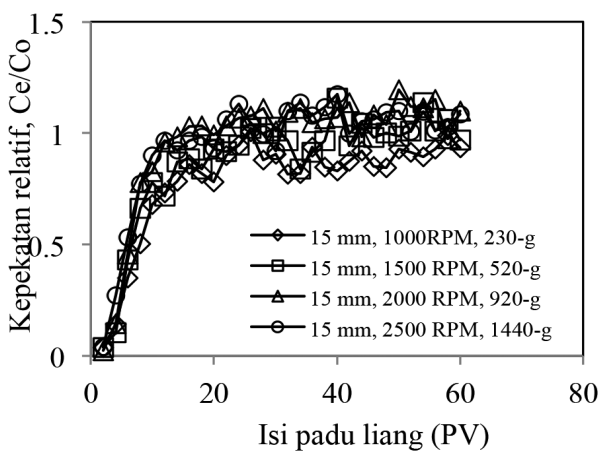

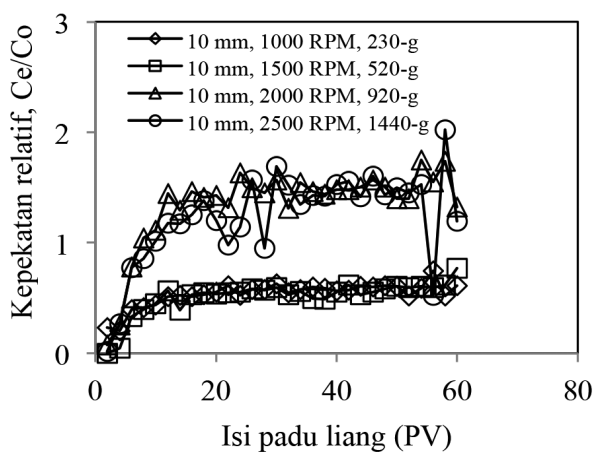

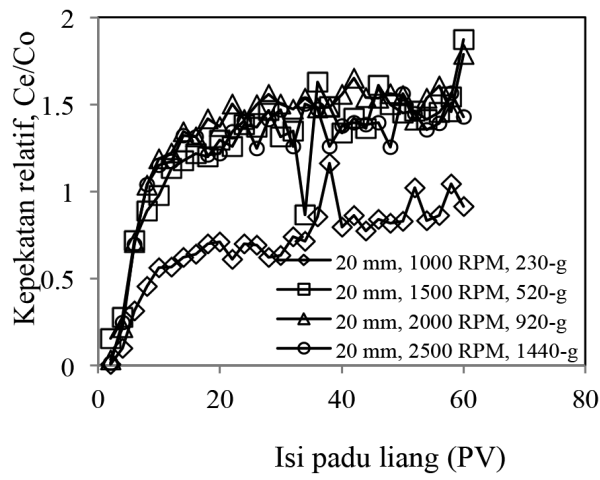

RAJAH 2. Hasil keputusan ujian mini kolum turasan bagi halaju/daya-G yang berbeza dengan menggunakan unsur $\mathrm{Cd}$ dalam larutan jenis tunggal (500 ppm) dan sampel tanah baki granit BGR berketebalan a) $10 \mathrm{~mm}$ b) $15 \mathrm{~mm}$ dan c) $20 \mathrm{~mm}$ 

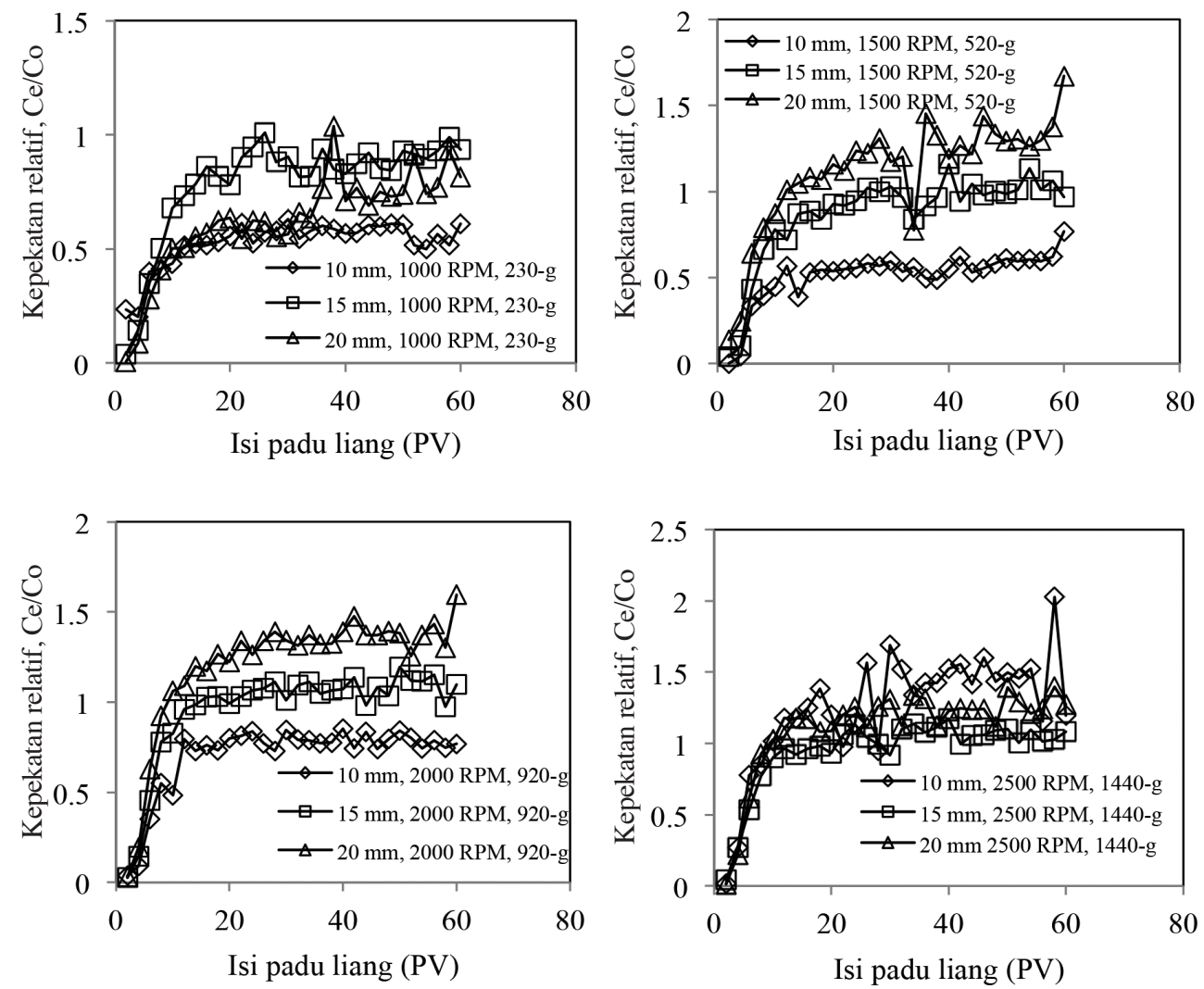

RAJAH 3. Hasil keputusan ujian mini kolum turasan berketebalan berbeza (10, 15 dan $20 \mathrm{~mm}$ ) dan menggunakan larutan jenis tunggal (500 ppm) pada halaju a) $1000 \mathrm{RPM}$ b) $1500 \mathrm{RPM}$ c) $2000 \mathrm{RPM}$ dan d) $2500 \mathrm{RPM}$
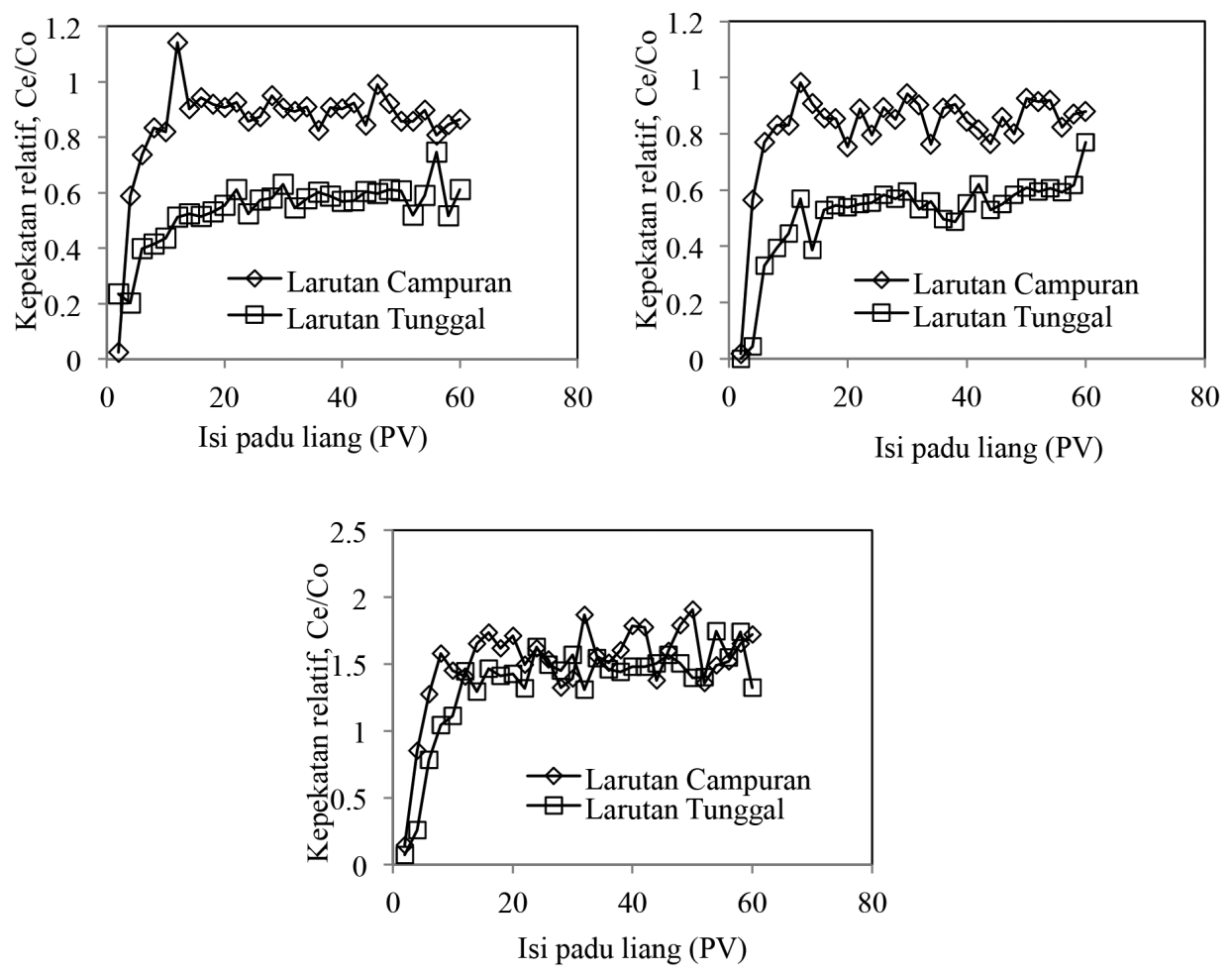

RAJAH 4. Hasil keputusan ujian mini kolum turasan bagi unsur Cd dalam larutan berbeza (iaitu tunggal atau campuran) dengan menggunakan sampel tanah baki granit BGR berketebalan $10 \mathrm{~mm}$ pada halaju a) $1000 \mathrm{rpm}$, b) $1500 \mathrm{rpm}$ dan c) $2000 \mathrm{rpm}$ 
JADUAL 3. Nilai $\mathrm{K}_{\mathrm{d}}$ bagi kesemua faktor yang dikaji

\begin{tabular}{|c|c|c|c|c|c|c|}
\hline \multirow[b]{2}{*}{$\begin{array}{c}\text { Berat } \\
(\mathrm{g})\end{array}$} & \multirow[b]{2}{*}{$\begin{array}{l}\text { Ketebalan } \\
(\mathrm{mm})\end{array}$} & \multirow[b]{2}{*}{$\begin{array}{l}\text { Halaju } \\
\text { (RPM) }\end{array}$} & \multirow[b]{2}{*}{$\begin{array}{c}\text { Daya } \\
(\mathrm{G})\end{array}$} & \multicolumn{3}{|c|}{$\mathrm{K}_{\mathrm{d}}(\mathrm{L} / \mathrm{kg})$} \\
\hline & & & & $\begin{array}{l}\text { Larutan tunggal } \\
\quad(500 \mathrm{ppm})\end{array}$ & $\begin{array}{c}\text { larutan } \\
\text { ccampuran } \\
(500 \mathrm{ppm})\end{array}$ & $\begin{array}{l}\text { larutan campuran } \\
\quad(100 \mathrm{ppm})\end{array}$ \\
\hline \multirow{4}{*}{10} & \multirow{4}{*}{10} & 1000 & 230 & 0.514 & 0.777 & 0.498 \\
\hline & & 1500 & 520 & 23.449 & 1.079 & 0.358 \\
\hline & & 2000 & 920 & 0.793 & 0.420 & 0.329 \\
\hline & & 2500 & 1440 & 0.981 & 0.417 & 0.188 \\
\hline \multirow{4}{*}{15} & \multirow{4}{*}{15} & 1000 & 230 & 0.668 & - & 0.229 \\
\hline & & 1500 & 520 & 0.648 & - & 0.182 \\
\hline & & 2000 & 920 & 0.811 & - & 0.192 \\
\hline & & 2500 & 1440 & 0.473 & - & 0.108 \\
\hline \multirow{4}{*}{20} & \multirow{4}{*}{20} & 1000 & 230 & 3.840 & - & 1.527 \\
\hline & & 1500 & 520 & 0.109 & - & 0.023 \\
\hline & & 2000 & 920 & 0.562 & - & 0.050 \\
\hline & & 2500 & 1440 & 1.448 & - & 0.0040 \\
\hline
\end{tabular}

disebabkan oleh wujudnya persaingan untuk menjerap ion logam berat dalam larutan campuran, mengurangkan jumlah penjerapan logam berat dan seterusnya menurunkan nilai $\mathrm{K}_{\mathrm{d}}$.

\section{$\mathrm{K}_{\mathrm{d}}$ DALAM KETEBALAN TANAH YANG BERBEZA}

Jadual 3 menunjukkan pada halaju 1500 rpm dalam larutan campuran (100 ppm), nilai $\mathrm{K}_{\mathrm{d}}$ bagi ketebalan $10 \mathrm{~mm}$ adalah $0.358 \mathrm{~L} / \mathrm{kg}$ manakala bagi ketebalan $20 \mathrm{~mm}$, nilai $\mathrm{K}_{\mathrm{d}}$ adalah $0.023 \mathrm{~L} / \mathrm{kg}$. Ini menunjukkan semakin bertambah ketebalan lapisan tanah semakin berkurang nilai $\mathrm{K}_{\mathrm{d}}$. Menurut Gordon et al. (1990) dalam Cawley (1999), semakin meningkat ketebalan pelapik, semakin berkurang aliran bahan pencemar untuk mengalir dalam pelapik tersebut. Gupta et al. (2014) juga berpendapat, dos bahan penjerap yang rendah juga menyebabkan peningkatan kadar penjerapan logam berat. Pada dos bahan penjerap yang tinggi, tapak tenaga (tapak aktif) yang tinggi berkurang disebabkan oleh banyak tapak tenaga yang lebih rendah diisi dan ini menyebabkan penjerapan logam daripada larutan bahan pencemar, $\mathrm{q}_{\mathrm{e}}$ dan nilai $\mathrm{K}_{\mathrm{d}}$ turut berkurang. Walau bagaimanapun, terdapat sampel yang mempunyai nilai $\mathrm{K}_{\mathrm{d}}$ yang terlalu tinggi seperti pada sampel berketebalan $15 \mathrm{~mm}$ dan berhalaju $2000 \mathrm{rpm}$ dan ia menunjukkan nilai $\mathrm{K}_{\mathrm{d}}$ sebanyak $0.811 \mathrm{~L} / \mathrm{kg}$. Ini mungkin berlaku disebabkan oleh retakan yang berlaku pada lapisan tanah.

\section{KAPASITI PENAMPAN}

Keupayaan tanah untuk mengekalkan (menjerap) logam berat dalam tanah bergantung kepada kapasiti penampan tanah dan ia diukur berdasarkan lengkung nilai $\mathrm{pH}$ larutan efluen. Rajah 5 menunjukkan keputusan nilai pH larutan efluen dalam larutan jenis tunggal (500 ppm). Nilai pH awal bagi larutan pencemar adalah pH5.82. Bagi ketigatiga graf, nilai $\mathrm{pH}$ pada $1 \mathrm{PV}$ adalah berjulat antara $\mathrm{pH} 6$ hingga pH6.8 dan selepas 4 PV, ia menurun secara malar pada $\mathrm{pH} 4$ sehingga $60 \mathrm{PV}$. Secara keseluruhannya, tanah baki granit mempunyai julat $\mathrm{pH}$ yang berasid dan ini menunjukkan kapasiti penampan bagi sampel tanah ini adalah sangat rendah (Zuhairi et al. 2008b) disebabkan oleh tanah baki granit mempunyai keupayaan untuk menahan daripada sebarang perubahan $\mathrm{pH}$ yang rendah. Menurut Kyzio (2002), kapasiti penampanan yang rendah menunjukkan keupayaan untuk bergabung antara partikel tanah dengan ion logam berat adalah rendah dan ini menyebabkan kadar penjerapan logam turut rendah (Wang \& Nan 2009).

\section{KESIMPULAN}

Kajian pergerakan logam berat cadmium $(\mathrm{Cd})$ oleh tanah baki granit menunjukkan keupayaan tanah baki granit untuk menjerap logam berat bergantung kepada sifat fizikokimia tanah. Keputusan analisis menunjukkan tanah baki granit mempunyai kapasiti penampan yang rendah dan menyebabkan kadar penjerapan logam turut rendah. Kajian ini juga mendapati pergerakan Cd bergatung kepada halaju/ daya-G, ketebalan lapisan tanah dan jenis larutan yang digunakan. Semakin tinggi halaju/daya-G, semakin cepat pergerakan Cd melalui tanah. Ini akan mengurangkan masa interaksi antara $\mathrm{Cd}$ dan partikel tanah dan menyebabkan penjerapan Cd berkurang. Urutan kapasiti penjerapan yang semakin menaik adalah seperti berikut; $2500 \mathrm{rpm}$ (1440 g) $<2000 \mathrm{rpm}(920 \mathrm{~g})<1500 \mathrm{rpm}(520 \mathrm{~g})<1000 \mathrm{rpm}(230 \mathrm{~g})$. Ketebalan lapisan tanah juga mempengaruhi pergerakan Cd melalui tanah. Lengkung bulus menunjukkan pergerakan Cd adalah berkadar secara songsang dengan ketebalan lapisan tanah di dalam kolum. Jumlah Cd yang terjerap oleh tanah baki granit dalam larutan campuran adalah rendah berbanding larutan tunggal. Kesimpulannya, dengan menggunakan ujian fiziko-kimia dan mini kolum turasan, pergerakan logam berat melalui tanah baki dapat diketahui dan kajian ini adalah sangat berkesan dalam memberi nilai penjerapan dengan lebih jitu. 

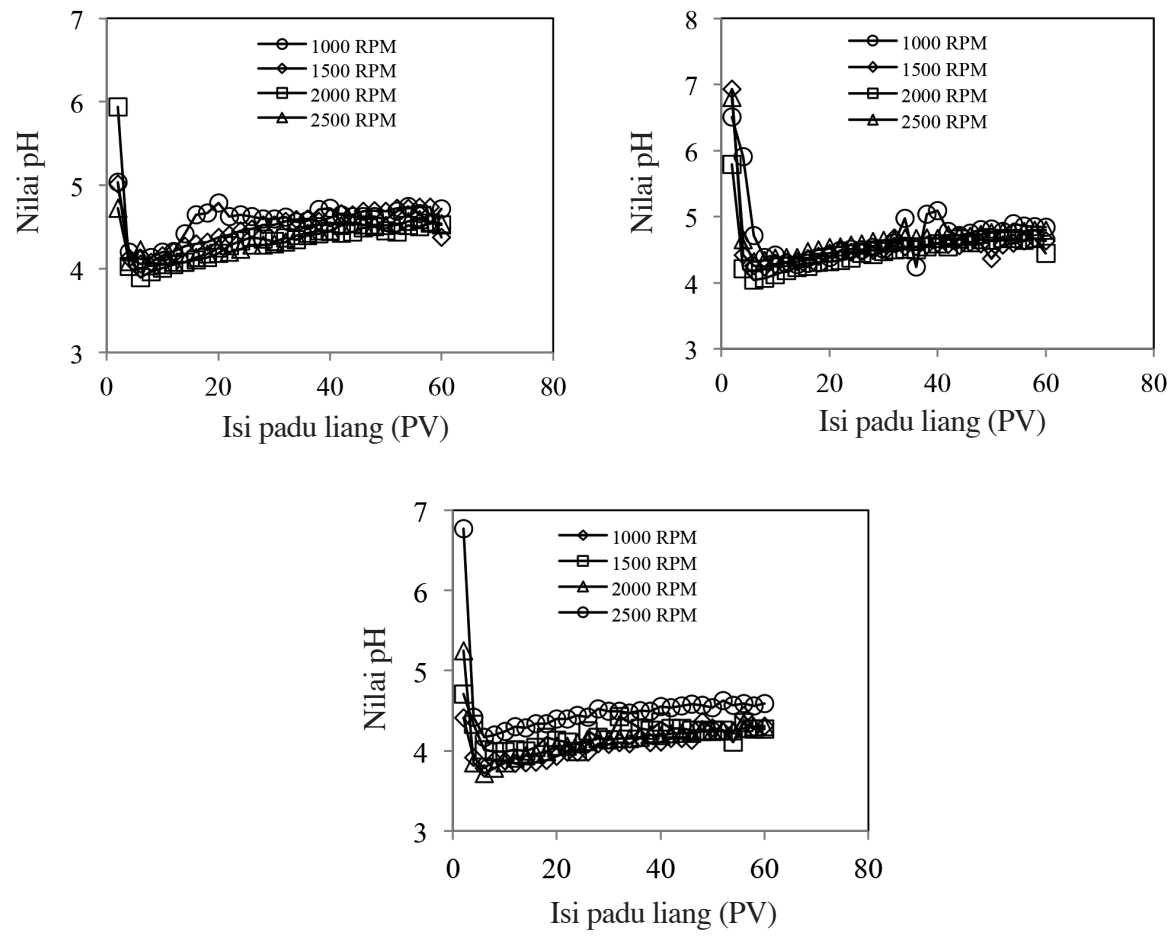

RAJAH 5. Hasil keputusan nilai pH larutan efluen dalam larutan jenis tunggal (500 ppm) bagi tanah baki granit BGR berketebalan a) $10 \mathrm{~mm}$ b) $15 \mathrm{~mm}$ dan c) $20 \mathrm{~mm}$

\section{PENGHARGAAN}

Penyelidikan ini menggunakan Dana Fundamental Research Grant Scheme, No. Projek: FRGS/1/2012/ STWN06/UKM/02/2. Penulis juga mengucapkan terima kasih kepada Program Geologi, Universiti Kebangsaan Malaysia atas segala bantuan yang diperlukan semasa menjalankan kajian penyelidikan ini.

\section{RUJUKAN}

Alemayehu, E. \& Lennartz, B. 2009. Virgin volcanic rocks: Kinetics and equilibrium studies for the adsorption of cadmium from water. Journal of Hazardous Materials 169(1-3): 395-401.

Alshaebi, F.Y., Zuhairi, W.Y.W. \& Samsudin, A.R. 2010. Removal of arsenic from contaminated water by selected geological natural materials. Australian Journal of Basic \& Appllied Science 4(9): 4413-4422.

Alther, G. 2002. Using organoclays to enhance carbon filtration. Waste Management 22(5): 507-513.

Antoniadis, V., Mckinley, J.D. \& Zuhairi, W.Y.W. 2007. Singleelement and competitive metal mobility measured with column infiltration and batch tests. Journal of Environment Quality 60: 53-60.

Antoniadis, V. \& McKinley, J.D. 2000. Leaching tests in a laboratory centrifuge on zinc migration in London Clay. International Symposium on Physical Modelling and Testing in Environmental Geotechnics, France. hlm. 50-58.

Atanassova, I. 1999. Competitive effect of copper, zinc, cadmium, and nickel on ion adsorption and desorption by soil clays. Water Air Soil Pollut. 113: 115-125.

Cawley, M.R. 1999. Compacted Clay Liners: A Viable Solution for Landfill Leachate Containment. Brigham Young University Provo, UT
Chalermyanont, T., Arrykul, S. \& Charoenthaisong, N. 2009. Potential use of lateritic and marine clay soils as landfill liners to retain heavy metals. Waste Management 29(1): 117-127.

Cheyns, K., Mertens, J., Diels, J., Smolders, E. \& Springael, D. 2010. Monod kinetics rather than a first-order degradation model explains atrazine fate in soil mini-columns: Implications for pesticide fate modelling. Environmental Pollution 158(5): 1405-1411.

Devulapalli, S.S.N. \& Reddy, K.R. 1996. Effect of nonliner adsorption on contaminant transport through landfill clay liners. Proc. 2nd International Congress on Environmental Geotechnics, Osaka, Japan. hlm. 473-478.

Gordon, M.E., Huebner, P.M. \& Mitchell, G.R. 1990. Regulation, construction and performance of clay-lined landfills in Wisconsin. In Waste Containment Systems: Construction, Regulation, and Performance, Bonaparte, R. (ed). American Society of Civil Engineers, Reston, VA. pp. 14-29.

Gupta, V.K., Suhas, Nayak, A., Agarwal. S., Chaudhary, M. \& Tyagi, I. 2014. Removal of $\mathrm{Ni}$ (II) ions from water using scrap tire. Journal of Molecular Liquids 190: 215-222.

Kim, Y., Kim, K., Kang, H., Kim, W., Doh, S., Kim, D. \& Kim, B. 2007. The accumulation of radiocesium in coarse marine sediment: Effects of mineralogy and organic matter. Marine Pollution Bulletin 54: 1341-1350.

Kouame, I.K., Dibi, B., Koffi, K., Savane, I. \& Sandu, I. 2010. Statistical approach of assessing horizontal mobility of heavy metals in the soil of Akouedo Landfill nearby Ebrie Lagoon (Abidjan-Cote D'ivoire). International Journal of Conservation Science 1(3): 149-160.

Kumar, P.R. 2006. Contaminant transport through geotechnical centrifuge models. Environmental Monitoring Assessment 177: 215-233

Kyzio, J. 2002. Effect of physical properties and cation exchange capacity on sorption of heavy metals onto peats. Polish Journal of Environmental Studies 11(6): 713-718. 
Liew, C.Y. \& Zuhairi, W.Y.W. 2010. The adsorption of lead, copper, zinc, cadmium, cobalt and nickel in residual soils using batch and high speed centrifuge mini column test. Seminar UKM-UNRI Ke-6. hlm. 463-465.

Markiewicz-Patkowska, J., Hursthouse, A. \& Przybyla-Kij, H. 2005. The interaction of heavy metals with urban soils: Sorption behaviour of $\mathrm{Cd}, \mathrm{Cu}, \mathrm{Cr}, \mathrm{Pb}$ and $\mathrm{Zn}$ with a typical mixed brownfield deposit. Environment International 31: 513-521.

Mohan, D. \& Singh, K.P. 2002. Single- and multi-component adsorption of cadmium and zinc using activated carbon derived from bagasse--an agricultural waste. Water Research 36(9): 2304-2318.

Rosli, R., Karim, A.T.A., Latiff, A.A.A. \& Taha, M.R. 2008. Adsorption properties of $\mathrm{As}, \mathrm{Pb}$ and $\mathrm{Cd}$ in soft soil and meta-sedimentary residual soil. Engineering Postgraduate Conference (EPC). hlm. 1-9.

Wan Zuhairi, W.Y \& Abdul Rahim, S. 2007. Sorption parameters of $\mathrm{Pb}$ and $\mathrm{Cu}$ on natural clay soils from Selangor, Malaysia. Sains Malaysiana 36(2): 149-157.

Wang, S. \& Nan, Z. 2009. Copper sorption behavior of selected soils of the oasis in the middle reaches of Heihe River Basin, China. Soil and Sediment Contamination 18(1): 74-86.

Xie, H., Chen, Y., Ke, H., Tang, X. \& Chen, R. 2009. Analysis of diffusion-adsorption equivalency of landfill liner systems for organic contaminants. Journal of Environmental Sciences 21(4): 552-560
Yong, R.N., Zuhairi, W.Z.Y., Bentley, S.P., Harris, C. \& Tan, B.K. 2001. Partitioning of heavy metals on soil samples from column tests. Engineering Geology 60: 307-322.

Zuhairi, W.Y.W., Samsudin, A.R. \& Kong, T.B. 2008a. The sorption distribution coefficient of lead and copper on the selected soil samples from Selangor. Bulletin of the Geological Society of Malaysia 54: 21-25.

Zuhairi, W.Y.W., Samsudin, A.R. \& Ridwan, N. 2008b. The retention characteristics of heavy metals in natural soils using soil column experiment. The 12th International Conference of International Association for Computer Methods and Advances in Geomechanics (IACMAG), Goa, India, 1-6 October. hlm. 2405-2411.

Program Geologi

Pusat Pengajian Sains Sekitaran dan Sumber Alam

Fakulti Sains dan Teknologi

Universiti Kebangsaan Malaysia

43600 Bangi, Selangor Darul Ehsan

Malaysia

*Pengarang untuk surat-menyurat; email: aishahzarime@gmail. com

Diserahkan: 7 Jun 2016

Diterima: 11 Oktober 2016 